\title{
Burnout in health care providers working in the intensive care units of a tertiary care hospital, South India-a questionnaire-based survey
}

\author{
Meghana Sanil BSc RT, Glevita Machado BSc RT, Varun R Nayak BSc RT, MSc RT
}

\begin{abstract}
M Sanil, G Machado, VR Nayak. Burnout in health care providers working in the intensive care units of a tertiary care hospital, South India-a questionnaire-based survey. Can J Respir Ther 2021;57:68-72. doi: 10.29390/cjrt-2021-005.

Background: The intensive care unit (ICU) is a special section of the hospital where intense monitoring and patient care are required. Health care providers (HCPs) who work in the ICU are exposed to a stressful environment and, in the long run, this may lead to exhaustion and burnout. It is observed that the burnout in HCPs in the ICU may have an impact on patient care and the psychological wellbeing of the caregiver. Thus, we aimed to assess the burnout in HCPs working in the ICUs of a tertiary care hospital in South India.

Methods: A single-center, questionnaire-based survey was carried out by HCPs who work in the ICUs of a tertiary care hospital in South India. A Google form link was created after obtaining approval from the Institutional Ethics Committee. The link was then circulated to the HCPs who work in the ICU and the responses were collected. The Google form fetched data related to demographics, profession, area of work, duration of work per day, total days of work in the ICU during the work period, and details of night duty. The Oldenburg burnout inventory questionnaire was used to measure burnout in the HCPs.

Results: A total of $60 \mathrm{HCPs}$ with a mean age of $23.37 \pm 2.93$ years, consented and filled out the online questionnaire. Of the $60 \mathrm{HCPs}, 41$ (68.33\%) were females and $19(31.67 \%)$ were males. Most of the participants were working in adult medical ICUs. The overall burnout level in all the participants was $2.39 \pm 0.31$, with the exhaustion level being $2.45 \pm 0.43$ and the disengagement level being $2.32 \pm 0.31$. Between $70 \%$ and $80 \%$ of HCPs experienced high levels of burnout while working in the ICUs. Work area, work duration, sleep duration, and clinical experience had an impact on burnout levels of the HCPs.
\end{abstract}

Conclusion: Most of the HCPs who work in the ICU experience high levels of burnout. Lack of clinical experience in the ICU and long work hours with lack of sleep can increase burnout in the HCPs.

Key Words: burnout; disengagement; exhaustion; health care provider; ICU

\section{INTRODUCTION}

The intensive care unit (ICU) is a special section of the hospital that provides intensive treatment for acutely unwell patients. Critical care health care workers are those who treat and constantly monitor patients whose conditions are life-threatening [1]. Doctors, nurses, respiratory therapists, and other health care providers (HCPs) work continuously in the ICU to take comprehensive care of critically ill patients. The HCPs who work in the ICU will be in a stressful environment of the hospital due to an emergent requirement of patient care and a high rate of mortality and morbidity [2].

Stress is a feeling of emotional or physical tension and burnout is a mixture of exhaustion, cynicism, and perceived inefficacy arising from long-term job stress [3]. Burnout was described by Herbert Freudenberger as a set of symptoms including fatigue, frustration, malaise, and inefficacy $[3,4]$. HCPs can be affected by stress resulting in insomnia, irritability, and depressive syndrome, which in turn can affect their life as well as can have an impact on the quality of care they provide to the patients [5]. Literature has shown that long-term and continuous burnout can increase the risk of cardiovascular disease, alcohol dependence, and shorter life expectancy [6, 7]. Many studies have indicated that HCP burnout is detrimental to patient care and higher levels of burnout have been observed related to increased rates of both patient mortality and spread of hospital-transmitted infections [6, 8, 9].

Different studies have compared stress levels in health care workers by considering major entities like doctors and nurses. Also, there is a paucity of data about the burnout levels in all HCPs working in the ICUs, especially in India. Assessing burnout in HCPs working in the ICU may help to overcome the factors affecting burnout in the HCPs. The HCPs who work in the ICUs of our tertiary care hospital are doctors, nurses, and respiratory therapists. Thus, we aimed to assess the burnout in HCPs working in the ICUs of a tertiary care hospital, South India.

\section{MATERIALS AND METHOD}

A single-center, questionnaire-based survey was carried out with HCPs working in the ICUs of a tertiary care hospital in South India. HCPs, aged above 18 years and who worked in the ICU at least $2 \mathrm{~h}$ a day, every day for at least 1 month were included after obtaining ethical approval by the institutional ethics committee (IEC 194-2020), which was valid from March 2020 to September 2020. HCPs who had a previous diagnosis of stress or any other psychological issue and HCPs who were not willing to participate in the study were excluded. The convenience sampling

Department of Respiratory Therapy, Manipal College of Health Professions, Manipal Academy of Higher Education, Karnataka, India

Correspondence: Varun R Nayak, Department of Respiratory Therapy, Manipal College of Health Professions, Manipal Academy of Higher Education, Manipal, Karnataka-576104, India, Tel: +91 9972381165, E-mail: Varunr838@gmail.com

Published online at https://www.cjrt.ca on 04 June 2021 
method was used for the recruitment of the participants. By considering the total population of 150 and sample proportion for high burnout from previous a study [10] of $47 \%$ with the power of $80 \%$ and $p<0.05$, the sample size of 108 was calculated.

A link for the online survey was generated by adding all the necessary information to a Google form and the survey was open from April 2020 to August 2020. The survey included demographic data of the participants and the validated English language Oldenburg Burnout Inventory (OLBI) [11] questionnaire. The OLBI questionnaire is a standardized and validated tool used for assessing burnout in HCPs. All the questions of OLBI are simple to understand for the participants and easy to analyze for burnout. Demographic data collected were age, gender, health care profession, area of work (adult medical or neonatal ICU), duration of work per day, total days of work in the ICU during the work period, and details of night duty. The OLBI questionnaire consists of two subscales, mainly exhaustion and disengagement at the workplace. A total of 16 items were either positively or negatively framed to assess the two core dimensions of burnout, i.e., level of exhaustion (8 items) and level of disengagement (8 items). Each statement was marked with a four-point Likert scale.

The link for the online survey was sent to all the HCPs working in the ICUs through email and social media platforms. Participants could fill the questionnaire after accepting the informed consent. For the analysis of the data, variables were categorized into the following groups and then the burnout values were compared between the groups. The profession was categorized as physician, staff nurse, respiratory therapy intern, and respiratory therapy clinical. The respiratory therapy interns are the students who complete their 3 years of bachelor's program and work in the clinical areas of the hospital for 1 year, and respiratory therapy clinical practitioners are the respiratory therapists who work in the ICUs after completing the 4 years of the bachelor's program. Overall clinical experience in the ICU was divided as $<1$ year, $1-5$ year, and $>5$ years. Sleep duration was divided into $\leq 5 \mathrm{~h} /$ day and $\geq 6 \mathrm{~h} /$ day. Duration of work per day in the ICU was categorized as $\leq 6 \mathrm{~h} /$ day, $7-10 \mathrm{~h} /$ day, and $\geq 11 \mathrm{~h} /$ day.

The statistical analysis was carried out using SPSS version 20, South India, Asia, and R-commander. Descriptive statistics were used for representing demographic data. The normality of all the burnout scores was analyzed using the Shapiro-Wilk test. Burnout rates among the gender, work area, and sleep duration at night categories were compared using an independent $t$-test. One-way ANOVA was used to compare burnout among different health care professions, clinical experience, and duration of work per day. A p-value of $<0.05$ was considered statistically significant.

\section{RESULTS}

A total of $60 \mathrm{HCPs}$, with a mean age of $23.37 \pm 2.93$ years, consented and filled out the online questionnaire. Of the 60, 41 (68.33\%) were females and $19(31.67 \%)$ were males. Most of the participants were respiratory therapy interns and clinical practitioners followed by staff nurses. Overall, $71.67 \%$ of participants were working in the adult medical ICUs, whereas $28.33 \%$ of participants were working in the neonatal ICUs. The demographic and work details of all the HCPs are presented in Table 1.

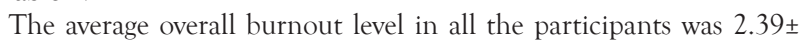
0.31 , with the exhaustion level being $2.45 \pm 0.43$ and the disengagement level being $2.32 \pm 0.31$. We considered an average cut-off burnout value of $\geq 2$ and we found that around 50 (83.3\%) HCPs had a burnout value of $\geq 2$. Peterson et al. [12] suggested a cut-off score of $\geq 2.25$ for exhaustion and $\geq 2.1$ for disengagement. Based on this cut-off value, around 43 (71.66\%) HCPs had high exhaustion, i.e., a score of $\geq 2.25$ and around $48(80 \%)$ of HCPs had high disengagement, i.e., a score of $\geq 2.1$. This suggests that between $70 \%$ and $80 \%$ of the HCPs experienced a high level of burnout. Comparison of overall burnout, exhaustion, and disengagement was analyzed among the gender, health profession, work area, overall clinical experience, duration of work per day, and duration of sleep at night. All the analysis details are presented in Table 2 .

\section{TABLE 1}

Demographic and work details of the participants into the study

\begin{tabular}{|c|c|c|}
\hline \multicolumn{2}{|c|}{ Demographic variables of the Participants $(n=60)$} & Value \\
\hline \multicolumn{2}{|c|}{ Age (years), mean (SD) } & $23.37(2.93)$ \\
\hline \multirow[t]{2}{*}{ Gender, $n(\%)$} & Male & 19 (31.67) \\
\hline & Female & $41(68.33)$ \\
\hline \multirow[t]{4}{*}{ Profession, $n(\%)$} & Physicians & $2(3.33)$ \\
\hline & Staff nurse & $20(33.33)$ \\
\hline & Respiratory therapy (intern) & $25(41.67$ \\
\hline & Respiratory therapy (clinical) & $13(21.67)$ \\
\hline \multirow[t]{2}{*}{ Work area, $n(\%)$} & Adult medical ICU & $43(71.67)$ \\
\hline & Neonatal ICU & $17(28.33)$ \\
\hline \multirow[t]{2}{*}{ Marital status, $n(\%)$} & Single & $54(10)$ \\
\hline & Married & $6(90)$ \\
\hline \multicolumn{2}{|c|}{$\begin{array}{l}\text { Overall work experience in the ICU, (months) } \\
\text { median (IQR) }\end{array}$} & $14.17(2.75,13.75)$ \\
\hline Overall clinical & $<1$ year & $18(30)$ \\
\hline \multirow[t]{2}{*}{ experience, $n(\%)$} & $1-5$ years & $35(58.33)$ \\
\hline & $>5$ year & $7(11.67)$ \\
\hline \multicolumn{2}{|c|}{ Overall work duration per week (hours), mean (SD) } & $41.12(15.98)$ \\
\hline \multicolumn{2}{|c|}{ Overall sleep duration at night (hours), mean (SD) } & $6.30(1.88)$ \\
\hline \multicolumn{2}{|c|}{ Total population who does night duty, $n(\%)$} & $53(88.33)$ \\
\hline
\end{tabular}

ICU = Intensive Care Unit.

No difference in burnout, exhaustion, and disengagement was found between males and females. Burnout, exhaustion, and disengagement were significantly lesser in HCPs working in the neonatal ICU than adult medical ICUs. Less sleep at night was associated with higher levels of burnout, and people who worked longer in the ICU had higher levels of burnout, exhaustion, and disengagement. There was no statistically significant difference in burnout, disengagement, and exhaustion when compared among the professions $(p>0.05)$

\section{DISCUSSION}

The ICU is a specialized unit of the hospital that requires continuous patient monitoring and intense care. HCPs are required to be actively present physically and mentally throughout their work. Apart from the intense work and burnout in the ICU, many other factors that mentally and physically drain the HCPs are mood, familial issues, organizational factors, psychological issues, stress, household workload, etc. It is observed that continuous burnout leads to emotional stress, fatigue, and loss of interest in one's own life [2-5]. Continuous exposure to high burnout situations may lead to alcohol dependence, sleep disturbances, cardiovascular abnormalities, and in extreme cases suicidal attempts [6-7]. As the burnout level in a person increases, there is a high chance that the person tends to miss important incidents happening in their environment. This is dangerous in a workplace like the ICU, because missing out on an important event may hamper patient care. As the burnout increases it is usual that the HCP may give less importance to universal precautions, infection control practices, and miss important alarms that can affect patient care. So, this study gives us insight into the burnout level of the HCPs who work in the ICU and the factors that can help in reducing the burnout level.

The OLBI questionnaire gives us two dimensions of burnout, i.e., disengagement of the staff and exhaustion in the workplace. Overall, high levels of burnout, exhaustion, and disengagement were observed in the HCPs working in our ICUs. Around $83.3 \%$ of HCPs showed a burnout level of greater than two. When we considered the cut-off value for HCPs given by Peterson et al. [12], 71.66\% of HCPs had high exhaustion and around $80 \%$ of HCPs had high disengagement. Similar results were found by Saravanabavan et al. [13], i.e., high level of burnout in around $80 \%$ of the HCPs working in the ICUs of a tertiary care hospital. A study done by Guntupalli et al. [14] showed that between 50\% and $60 \%$ of Indian ICU HCPs show a moderate to a high degree of burnout. Studies by Saravanabavan et al. [13] and Guntupalli et al. [14] used Maslach Burnout Inventory-Human Service Survey (MBI-HSS) for 


\section{TABLE 2}

Comparison of burnout, exhaustion, and disengagement scores of health care providers working in the intensive care units

\begin{tabular}{|c|c|c|c|c|}
\hline Burnout components & Variables $(n=60)$ & & Mean (SD) & $P$ \\
\hline \multirow[t]{12}{*}{ Overall burnout } & Gender & Males $(n=19)$ & $2.38(0.34)$ & 0.96 \\
\hline & & Females $(n=41)$ & $2.39(0.24)$ & \\
\hline & Work area & Adult Medical ICU $(n=43)$ & $2.43(0.29)$ & 0.07 \\
\hline & & Neonatal ICU $(n=17)$ & $2.27(0.33)$ & \\
\hline & Overall clinical experience & $<1$ year $(n=18)$ & $2.44(0.29)$ & 0.15 \\
\hline & & $1-5$ years $(n=35)$ & $2.40(0.27)$ & \\
\hline & & $>5$ years $(n=7)$ & $2.18(0.47)$ & \\
\hline & Sleep duration per night & $\leq 5 \mathrm{~h} /$ night $(n=10)$ & $2.54(0.20)$ & 0.08 \\
\hline & & $\geq 6$ h/night $(n=50)$ & $2.35(0.32)$ & \\
\hline & Work duration per day & $\leq 6 \mathrm{~h} /$ day $(n=29)$ & $2.34(0.37)$ & 0.42 \\
\hline & & $7-10$ h/day $(n=19)$ & $2.39(0.22)$ & \\
\hline & & $\geq 11$ h/day $(n=12)$ & $2.48(0.27)$ & \\
\hline \multirow[t]{12}{*}{ Exhaustion } & Gender & Males $(n=19)$ & $2.41(0.37)$ & 0.61 \\
\hline & & Females $(n=41)$ & $2.47(0.46)$ & \\
\hline & Work area & Adult Medical ICU $(n=43)$ & $2.49(0.41)$ & 0.24 \\
\hline & & Neonatal ICU $(n=17)$ & $2.35(0.46)$ & \\
\hline & Overall clinical experience & $<1$ year $(n=18)$ & $2.52(0.44)$ & 0.27 \\
\hline & & $1-5$ years $(n=35)$ & $2.46(0.40)$ & \\
\hline & & $>5$ years $(n=7)$ & $2.21(0.53)$ & \\
\hline & Sleep duration per night & $\leq 5 \mathrm{~h} /$ night $(n=10)$ & $2.67(0.31)$ & 0.069 \\
\hline & & $\geq 6 \mathrm{~h} /$ night $(n=50)$ & $2.40(0.44)$ & \\
\hline & Work duration per day & $\leq 6 \mathrm{~h} /$ day $(n=29)$ & $2.40(0.45)$ & 0.32 \\
\hline & & $7-10$ h/day $(n=19)$ & $2.43(0.36)$ & \\
\hline & & $\geq 11 \mathrm{~h} /$ day $(n=12)$ & $2.61(0.48)$ & \\
\hline \multirow[t]{12}{*}{ Disengagement } & Gender & Males $(n=19)$ & $2.37(0.27)$ & 0.41 \\
\hline & & Females $(n=41)$ & $2.30(0.31)$ & \\
\hline & Work area & Adult Medical ICU $(n=43)$ & $2.37(0.28)$ & 0.04 \\
\hline & & Neonatal ICU $(n=17)$ & $2.20(0.33)$ & \\
\hline & Overall clinical experience & $<1$ year $(n=18)$ & $2.36(0.25)$ & 0.24 \\
\hline & & $1-5$ years $(n=35)$ & $2.34(0.29)$ & \\
\hline & & $>5$ years $(n=7)$ & $2.14(0.46)$ & \\
\hline & Sleep duration per night & $\leq 5 \mathrm{~h} /$ night $(n=10)$ & $2.40(0.29)$ & 0.37 \\
\hline & & $\geq 6$ h/night $(n=50)$ & $2.31(0.30)$ & \\
\hline & Work duration per day & $\leq 6 \mathrm{~h} /$ day $(n=29)$ & $2.29(0.35)$ & 0.73 \\
\hline & & $7-10 \mathrm{~h} /$ day $(n=19)$ & $2.35(0.27)$ & \\
\hline & & $\geq 11$ h/day $(n=12)$ & $2.35(0.23)$ & \\
\hline
\end{tabular}

assessing burnout, which is a valid tool for assessing burnout in HCPs. A lesser burnout was observed by Sidiq et al. [15] in doctors working in the North Indian state; overall, it showed that around $50 \%-80 \%$ of Indian HCPs experience a high level of burnout.

There was no significant difference observed in burnout levels between males and females. However, Sidiq et al. [15] used the General Health Questionnaire and showed slightly higher stress in females than males. When compared between the work areas, HCPs who work in neonatal ICU had less burnout than those in the adult medical ICU. Also, the disengagement level in HCPs working in the adult ICU is significantly higher than in the neonatal ICU. Lazaridou et al. [16] showed similar results that the burnout in pediatric ICU was higher than the NICU. This may be because of the ease of care required in neonatal ICUs. It is also observed that the senior and experienced HCPs work in neonatal ICU. A lower level of experience in the adult ICU and high turnover might have been the contributing factors for increased burnout in the adult ICU HCPs.

Our study did not show any significant difference in burnout levels when compared among the health care professions. We observed a lesser burnout, exhaustion, and disengagement in people who are experienced than the nonexperienced people. HCPs who had a clinical experience of $<1$ year had a trend towards a greater level of burnout than the HCPs who had $>5$ years of clinical experience. Similar results are observed by Aytekin et al. [17] and Özden et al. [18]. This suggests that the HCPs should be adequately trained in the wards or high-dependency units before posting to the ICU. Adequate training in the low-stress clinical environment and giving observation periods for a specific time in the ICU might help them adjust to the work environment and lower burnout.
We also observed that as the work duration in the ICU increases the burnout and exhaustion in HCPs increase. Even though there is no statistically significant difference there is a trend in increased burnout and exhaustion in HCPs who are working for more than $11 \mathrm{~h}$. A similar result was observed in nurses by Stimpfel [19]. A longer duration of work can have a significant impact on the HCPs who work in a stressful environment like the ICU. Work duration of fewer than $10 \mathrm{~h}$ a day with adequate breaks will be beneficial for reducing burnout and stress in the ICU. Cordoza et al. [20] have shown that taking adequate breaks can reduce stress and burnout.

Sleep is one of the important factors that can affect burnout. We found that the people who slept for more than $6 \mathrm{~h}$ had less burnout, disengagement, and exhaustion during work than the people who slept for less than $5 \mathrm{~h}$. Similar results were observed by Wisetborisut et al. [21] who also proposed that adequate sleep hours and duty-offs may protect the HCPs from burnout. The effect of sleep deprivation on HCP burnout level is not well understood. Metlaine et al. [22] studied the effect of sleep and biological parameters on burnout using the MBI-HSS questionnaire and found that insomnia causes a significant increase in burnout level. Stewart et al. [23] observed that sleep deprivation increases clinical burnout in physicians and proposed early detection and management of the burnout. Stewart et al. [23] also proposed that studies are required to understand the role of sleep on burnout in HCPs. Promotion of adequate sleep for the day shift HCPs and keeping minimal night-duty days in a stretch or giving duty off between the continuous night duties might help in reducing burnout. None of the participants reported any psychological issues.

The COVID-19 pandemic has emerged as the biggest health care crisis worldwide and all HCPs are working selflessly in tackling the 
situation. In India, respiratory therapists are working in an intense work environment like ICUs and emergency departments along with the other major health care entities like physicians and nurses [24]. A series of studies have been conducted for assessing burnout in major health care entities working in the COVID care units and found high levels of burnout [25-30]. Even though the HCPs who participated in our study were not exposed to COVID-19 patients, the high level of burnout in HCPs might have been impacted by the COVID-19 pandemic. The major contributing factors found by the different studies might have contributed to the high level of burnout in our study. The major factors found by the different studies are the fear of transmission of infection to self and family members, use of heavy PPE, reduced number of HCPs in the ICU, inadequate training on infection control practices, and general pandemic fatigue [25-31]. The majority of the studies suggested assessing burnout in HCPs periodically and taking necessary measures to improve the mental health of the HCPs.

Most of the studies have used MBI-HSS for assessing burnout in the HCPs and the results are comparable with the data obtained from this study. There is minimal evidence available in the Indian population regarding the work-related stress and burnout in HCPs working in the ICU. Scrutinizing HCPs for stress and burnout should be considered by all the hospitals/ health care institutions. Periodic assessment of burnout in HCPs and adjusting the risk factors will help to improve the HCPs' job satisfaction and psychological wellbeing and stop the spread of infection to self and the patients. HCPs with high burnout may be considered for psychological counselling for practicing coping skills and lifestyle modifications.

\section{LIMITATIONS AND FUTURE DIRECTIVES}

This was a single-center study, and we could not reach the calculated sample size. The hospital reduced the ICU staff during the study period as per the COVID-19 pandemic guidelines and based on our inclusion/exclusion criteria we missed some of the HCPs that limited the required sample size. In this study, we could not assess the impact of organizational factors on HCPs' burnout. In the future, multicentre studies should be conducted in the Indian population to better understand the optimal duty timings, optimal night shifts, and requirement of adequate breaks while working in the ICUs. Future studies should also focus on providing psychological support for the ICU HCPs and assessing their burnout levels.

\section{CONCLUSION}

The majority of the HCPs who work in the ICU experience a high level of burnout, disengagement, and exhaustion. The major factors that impact burnout are the longer duty hours, lack of clinical experience, and lack of sleep. Importance should be given for periodic assessment of burnout in HCPs working in the ICU and adequate measures should be taken to reduce the burnout.

\section{Conflicts of Interest}

\section{DISCLOSURES}

There are no conflict of interest related to this manuscript.

\section{Funding Source}

This study did not receive any grant from funding agencies in the public, commercial, or not-for-profit sectors.

\section{Ethical Approval}

Approval was granted by the institutional ethics committee (IEC 1942020), valid from March 2020 to September 2020.

\section{REFERENCES}

1. Embriaco N, Papazian L, Kentish-Barnes N, Pochard F, Azoulay E. Burnout syndrome among critical care healthcare workers. Curr Opin Crit Care 2007; 13(5): 482-8. doi: 10.1097/MCC.0b013e3282efd28a

2. Kumar A, Pore P, Gupta S, Wani AO. Level of stress and its determinants among intensive care unit staff. Indian J Occup Environ Med 2016; 20(3): 129. doi: 10.4103/0019-5278.203137
3. Reith TP. Burnout in United States healthcare professionals: a narrative review. Cureus 2018; 10(12). doi: 10.7759/cureus.3681

4. Freudenberger HJ. Staff burn-out. J Soc Issues 1974; 30(1): 159-65. doi: 10.1111/j.1540-4560.1974.tb00706.x

5. Merlani P, Verdon M, Businger A, Domenighetti G, Pargger H, Ricou B. Burnout in ICU caregivers: a ulticentre study of factors associated to centers. Am J Respir Crit Care Med 2011; 184(10): 1140-6. doi: 10.1164/ rccm.201101-00680C

6. Shanafelt TD, Balch CM, Bechamps G, et al. Burnout and medical errors among American surgeons. Ann Surg 2010; 251(6): 995-1000. doi: 10.1097/SLA.0b013e3181bfdab3

7. Shanafelt TD, Gradishar WJ, Kosty M, et al. Burnout and career satisfaction among US oncologists. J Clin Oncol 2014; 32(7): 678. doi: 10.1200/ JCO.2013.51.8480

8. Welp A, Meier LL, Manser T. Emotional exhaustion and workload predict clinician-rated and objective patient safety. Front Psychol 2015; 5: 1573. doi: 10.3389/fpsyg.2014.01573

9. Cimiotti JP, Aiken LH, Sloane DM, Wu ES. Nurse staffing, burnout, and health care-associated infection. Am J Infect Contr 2012; 40(6): 486-90. doi: 10.1016/j.ajic.2012.02.029

10. Dahlin ME, Runeson B. Burnout and psychiatric morbidity among medical students entering clinical training: a three year prospective questionnaire and interview-based study. BMC Med Educ 2007; 7(1): 6. doi: $10.1186 / 1472-6920-7-6$

11. Demerouti E, Mostert K, Bakker AB. Burnout and work engagement: a thorough investigation of the independency of both constructs. J Occup Health Psychol 2010; 15(3): 209. doi: 10.1037/a0019408

12. Peterson U, Demerouti E, Bergström G, Samuelsson M, Asberg M, Nygren A. Burnout and physical and mental health among Swedish healthcare workers. J Adv Nurs 2008; 62(1): 84-95. doi: 10.1111/j.1365-2648.2007.04580.x

13. Saravanabavan L, Sivakumar MN, Hisham M. Stress and burnout among intensive care unit healthcare professionals in an Indian Tertiary Care hospital. Indian J Crit Care Med 2019; 23(10): 462. doi: 10.5005/ jp-journals-10071-23265

14. Guntupalli KK, Wachtel S, Mallampalli A, Surani S. Burnout in the intensive care unit professionals. Indian J Crit Care Med 2014; 18: 139-43. doi: 10.4103/0972-5229.128703

15. Suhail S, Abdul WM, Javid A, Rayees N, Bhatsheeba A, Mohamad AS. Stress levels of doctors working in critical care units in a North Indian State. Int J Contemp Med Res 2017; 4(3): 625-8.

16. Lazaridou C, Agakidou E, Diamanti E, Agakidis C. Burnout in doctors and nurses working in neonatal and pediatric intensive care units in a General Hospital. Aristotle Univ Med J 2011; 38(3): 37-43.

17. Galván ME, Vassallo JC, Rodríguez SP, et al. Professional burnout in pediatric intensive care units in Argentina. Arch Argent Pediatr 2012; 110: 466-73. doi: 10.5546/aap.2012.eng.466

18. Özden D, Karagözoglu S, YıldırımG. Intensive care nurses' perception of futility: job satisfaction and burnout dimensions. Nurs Ethics 2013; 20: 436-47. doi: 10.1177/0969733012466002

19. Stimpfel AW, Sloane DM, Aiken LH. The longer the shifts for hospital nurses, the higher the levels of burnout and patient dissatisfaction. Health Aff 2012; 31(11): 2501-9. doi: 10.1377/ hlthaff.2011.1377

20. Makayla C, Ulrich RS, Manulik BJ, et al. Impact of nurses taking daily work breaks in a hospital garden on burnout. Am J Crit Care 2018; 27(6): 508-12. doi: 10.4037/ajcc2018131

21. Wisetborisut A, Angkurawaranon C, Jiraporncharoen W, Uaphanthasath R, Wiwatanadate P. Shift work and burnout among health care workers. Occup Med 2014; 64(4): 279-86. doi: 10.1093/ occmed/kqu009

22. Metlaine A, Sauvet F, Gomez-Merino D, et al. Sleep and biological parameters in professional burnout: a psychophysiological characterization. PloS One 2018; 13(1): e0190607. doi: 10.1371/journal. pone. 0190607

23. Stewart NH, Arora VM. The impact of sleep and circadian disorders on physician burnout. Chest 2019; 156(5): 1022-30. doi: 10.1016/j. chest.2019.07.008

24. Sawadkar MM, Nayak VR. Respiratory therapists: the unnoticed warriors during COVID-19 pandemic in India. Can J Respir Ther 2020; 56: 57. doi: $10.29390 /$ cjrt-2020-044

25. Lasalvia A, Amaddeo F, Porru S, et al. Levels of burn-out among healthcare workers during the COVID-19 pandemic and their associated factors: a cross-sectional study in a tertiary hospital of a highly burdened 


\section{Sanil et al.}

area of north-east Italy. BMJ Open 2021; 11(1): e045127. doi: 10.1136/ bmjopen-2020-045127

26. Azoulay E, De Waele J, Ferrer R, et al. Symptoms of burnout in intensive care unit specialists facing the COVID-19 outbreak. Ann Intensive Care 2020; 10(1): 1-8. doi: 10.1186/s13613-020-00722-3

27. Sasangohar F, Jones SL, Masud FN, Vahidy FS, Kash BA. Provider burnout and fatigue during the COVID-19 pandemic: lessons learned from a high-volume intensive care unit. Anesth Analg 2020. doi: 10.1213/ ANE. 0000000000004866

28. Bradley M, Chahar P. Burnout of healthcare providers during COVID-19 system. Cleve Clin Med J 2020; 5(9): 10. doi: 10.3949/ccjm.87a.ccc051
29. Morgantini LA, Naha U, Wang $\mathrm{H}$, et al. Factors contributing to healthcare professional burnout during the COVID-19 pandemic: a rapid turnaround global survey. PloS One 2020; 15(9): e0238217. doi: 10.1371/ journal.pone.0238217

30. Khasne RW, Dhakulkar BS, Mahajan HC, Kulkarni AP. Burnout among healthcare workers during COVID-19 pandemic in India: results of a questionnaire-based survey. Indian J Crit Care Med 2020; 24(8): 664. doi: $10.5005 /$ jp-journals-10071-23518

31. Mehta S, Machado F, Kwizera A, et al. COVID-19: a heavy toll on health-care workers. Lancet Respir Med 2021; 9(3): 226-8. doi: 10.1016/ S2213-2600(21)00068-0 